\title{
WT1-associated protein is a novel prognostic factor in pancreatic ductal adenocarcinoma
}

\author{
BING-QI LI ${ }^{1 *}$, SHUAI HUANG ${ }^{*}$, QIAN-QIAN SHAO ${ }^{1}$, JIAN SUN $^{2}$, LI ZHOU $^{1}$, LEI YOU ${ }^{1}$, \\ TAI-PING ZHANG ${ }^{1}$, QUAN LIAO ${ }^{1}$, JUN-CHAO GUO ${ }^{1}$ and YU-PEI ZHAO ${ }^{1}$ \\ Departments of ${ }^{1}$ General Surgery and ${ }^{2}$ Pathology, Peking Union Medical College Hospital, \\ Chinese Academy of Medical Sciences/Peking Union Medical College, Beijing 100730, P.R. China
}

Received June 29, 2015; Accepted September 27, 2016

DOI: $10.3892 / \mathrm{ol} .2017 .5784$

\begin{abstract}
Although Wilms tumor 1 (WT1)-associated protein (WTAP) was initially found to be a specific WT1-binding protein, it has increasingly attracted attention because of its oncogenic role in various types of malignancies, including cholangiocarcinoma, glioblastoma and acute myeloid leukemia. However, the clinical impact of WTAP on pancreatic ductal adenocarcinoma (PDAC) is still unknown. A total of 145 patients who underwent surgical treatment from 2004 to 2008 were enrolled in the present study. The cytoplasmic and nuclear expression of WTAP in tumor and adjacent normal tissues was examined by immunohistochemical analysis in order to investigate the relationship between WTAP and the clinicopathological factors and prognosis of patients with PDAC. The nuclear and cytoplasmic expression of WTAP in tumor tissues was significantly higher compared with non-tumor tissues $(\mathrm{P}<0.001)$. High expression of WTAP in the nucleus was significantly associated with gender $(\mathrm{P}=0.010)$ and tumor stage $(\mathrm{P}=0.020)$, while high expression of WTAP in the cytoplasm was significantly associated with gender $(\mathrm{P}=0.018)$, histological grade $(\mathrm{P}=0.047)$ and perineural invasion $(\mathrm{P}=0.028)$. In addition, a univariate analysis revealed that high nuclear expression of WTAP in tumor tissues was significantly associated with poor overall survival $(\mathrm{P}<0.001)$, as well as several clinicopathological variables, including gender and $\mathrm{N}$ stage. In a multivariate Cox regression analysis, nuclear WTAP expression was identified as
\end{abstract}

Correspondence to: Professor Yu-Pei Zhao or Professor Jun-Chao Guo, Department of General Surgery, Peking Union Medical College Hospital, Chinese Academy of Medical Sciences/Peking Union Medical College, 1 Shuai-Fu-Yuan, Wang-Fu-Jing Street, Dong-Cheng, Beijing 100730, P.R. China

E-mail: zhao8028@263.net

E-mail: gjcpumch@163.com

*Contributed equally

Key words: immunohistochemistry, pancreatic ductal adenocarcinoma, prognosis, tissue microarray, Wilms tumor 1-associated protein an independent prognostic indicator for PDAC (relative risk, 1.855; 95\% confidence interval, 1.033-3.333; $\mathrm{P}=0.039$ ). The results of the present study indicated that high nuclear expression of WTAP is a valuable molecular biomarker of a poor prognosis among patients with PDAC.

\section{Introduction}

Pancreatic ductal adenocarcinoma (PDAC) is the fourth leading cause of cancer-associated mortality in the USA (1) and the seventh most common cause of cancer-associated mortality worldwide (2). However, it has a relatively low incidence rate, ranking eleventh among men and twelfth among women in developed countries (2). In America, it was estimated that 53,070 new patients will be diagnosed and 41,780 patients will succumb to PDAC in 2016 (3). Furthermore, in China, reports from the China's Disease Surveillance Point System showed that the age-adjusted mortality rate of patients with PDAC increased from 2.18 per 100,000 individuals in 1991 to 3.26 per 100,000 individuals in 2000 (4). Notably, the overall 5 -year survival rate worldwide for this disease is $<5 \%$ (5), or $7 \%$ for the USA, despite being the most advanced nation in terms of medicine (1). Estimates indicate that PDAC will be second only to non-small-cell lung cancer as the leading cause of cancer-related mortality in the USA by 2030 (6). In addition, although complete surgical resection is the only therapy with a possibility for long-term survival (7), the 5-year survival rate of patients who have undergone surgical resection is only $15-20 \%$ (8). This extremely poor prognosis mostly results from its insidious onset and rapid progression. Furthermore, no effective screening test for predicting the prognosis of PDAC is available. Therefore, factors predictive of a poor disease prognosis are of interest. Lymph node metastasis, perineural invasion (PNI) and resection margins, which are conventional clinical and pathological parameters, were previously identified as significant variables (9-11). Increasingly, attention is being paid to tumor initiation/progress-associated molecules that are associated with the prognosis of PDAC $(12,13)$. However, more promising biomarkers are required.

Wilms tumor 1 (WT1)-associated protein (WTAP), which is a nuclear protein, was first identified by Little et al (14) in 2000 because of its specific interaction with WT1. However, WTAP has also been shown to have a close relationship with 
malignant tumors. For instance, WTAP was shown to be overexpressed in cholangiocarcinoma, in particular in patients with lymph node metastasis or vascular invasion (15). Further analysis of the relationship between WTAP and clinicopathological characteristics demonstrated that the expression level of WTAP was closely associated with the tumor-node-metastasis stage (16). In addition, in vitro assays showed that WTAP has an important role in the migration and invasion of cholangiocarcinoma cells, which was also demonstrated for glioblastoma (16). Notably, WTAP was overexpressed in glioblastoma and was associated with the prognosis of patients with glioblastoma (16). Besides solid tumors, an oncogenic role for WTAP was also observed in acute myeloid leukemia (AML) (17). WTAP expression was able to promote the proliferation and inhibit the differentiation of AML cells. However, to the best of our knowledge, no previous studies have investigated the relationship between WTAP and PDAC. Therefore, the present study aimed to evaluate the expression of WTAP in PDAC and its association with the clinicopathological factors and prognosis of patients with PDAC.

\section{Materials and methods}

Patients and tissue samples. PDAC tissues and adjacent normal tissues were obtained from 145 patients who underwent radical surgical resection (R0) at Peking Union Medical College Hospital (Beijing, China) between September 2004 and December 2008. The present study was approved by the Peking Union Medical College Hospital Ethical Committee. Informed consent was obtained from all patients. The diagnosis of PDAC for all patients was confirmed pathologically, according to the World Health Organization criteria (18). Adjacent normal tissues were obtained from the resected specimen as far as possible from the cancer lesion. The clinical and pathological data included patient demographics (age and gender), tumor size, tumor location, degree of histological differentiation, tumor stage ( $\mathrm{T}$ stage), lymph node stage ( $\mathrm{N}$ stage) and complete follow-up records. The clinicopathological variables of the patients are shown in Table I.

Tissue microarray (TMA) construction. TMAs were constructed using formalin-fixed, paraffin-embedded blocks of PDAC and adjacent normal tissues. Diagnosis was confirmed by a hematoxylin-eosin staining-based routine pathological examination. Following a review and screening of the representative tumor regions, two tissue cores for each patient were sampled using a $1.5-\mathrm{mm}$ punch. TMA construction was performed using a manual tissue arrayer (Beecher Instruments, Inc., Sun Prairie, WI, USA).

Immunohistochemical staining. TMA-based immunohistochemical staining for WTAP was performed in tissues from 145 patients with PDAC using a rabbit anti-human WTAP polyclonal antibody (cat. no. ab155655; Abcam, Cambridge, UK) and a two-step staining kit (EnVision ${ }^{\mathrm{TM}}$ Detection System, Peroxidase/DAB, Rabbit/Mouse; Dako, Glostrup, Denmark). The tissues were cross-sectioned (4- $\mu \mathrm{m}$ thick), mounted, deparaffinized with xylene (XILONG Chemical Co., Ltd., Shanghai, China) and rehydrated with a graded ethanol series (100, 95 and 75\%), after which antigens were retrieved by autoclaving with $0.01 \mathrm{M}$ citrate buffer at $95^{\circ} \mathrm{C}$ for $10 \mathrm{~min}$. Slides were subsequently incubated with $3 \%$ hydrogen peroxide at $25^{\circ} \mathrm{C}$ for 10 min to block endogenous peroxidase activity, followed by incubation with the primary antibody (dilution, $1: 100$ ) overnight at $4^{\circ} \mathrm{C}$. Following washing in PBS, the slides were incubated with horseradish peroxidase-labeled secondary antibody (ready to use; EnVision ${ }^{\mathrm{TM}}$ Detection System, Peroxidase/DAB, Rabbit/Mouse; Dako) and, after washing with PBS, the slides were stained with diaminobenzidine and then counterstained with hematoxylin. Normal rabbit serum (cat. no. ab7487; Abcam) at the same dilution was applied as the negative control.

Staining evaluation. Two pathologists with no prior information of clinicopathological and survival data performed the staining evaluation using a light microscope. Controversies were resolved by reaching a consensus following a discussion. Nuclear and/or cytoplasmic brown coloration was defined as a positive signal. The two pathologists evaluated the percentage of positively stained cells and scored the intensity of tumor cell staining. The percentage of positive cells was classified into five grades: $0 \%$, grade $0 ; 1-24 \%$, grade $1 ; 25-49 \%$, grade $2 ; 50-74 \%$, grade 3 ; and $75-100 \%$, grade 4 . The staining intensity was classified into four grades: Primary score $=0$, grade 0 ; primary score $<1$, grade 1 ; primary score $\geq 1$ and $<1.5$, grade 2 ; and primary score $\geq 1.5$, grade 3 . When comparing the expression level of cytoplasmic/nuclear WTAP between tumor tissues and non-tumor tissues using the Mann-Whitney U test, the product of the above two grades was used as the final score. When investigating the prognostic significance of the cytoplasmic/nuclear expression level of WTAP, the ratio of the product of the percentage of positively stained cells and the primary intensity score of tumor cell staining between tumor and non-tumor tissues for each corresponding patient was used (cytoplasmic: low, ratio $<1.8$; high, ratio $\geq 1.8$; nuclear: low, ratio $<5.0$; high, ratio $\geq 5.0$ ).

Follow-up and evaluated variables. Follow-up after surgery was performed for all patients (median duration of follow-up, 13.2 months; range, 3-87 months). Eight general, clinical and pathological variables, including gender, age, tumor site, tumor size, grade, PNI and T/N stages, were evaluated.

Statistical analyses. WTAP staining between the tumor and non-tumor tissues was compared using the Mann-Whitney U test. The $\chi^{2}$ test was used to assess the association between WTAP expression and clinicopathological variables. Overall survival was calculated using the Kaplan-Meier method and analyzed by the log-rank test. Cox regression (proportional hazard model) was used to perform a multivariate analysis of prognostic factors. Statistical analyses were performed using SPSS 16.0 software (SPSS Inc., Chicago, IL, USA). P<0.05 was considered to indicate a statistically significant difference.

\section{Results}

Nuclear expression of WTAP in PDAC tissues and its association with clinicopathological features. Positive nuclear staining of WTAP was present in both tumor and non-tumor tissues (Fig. 1A and B). The nuclear WTAP staining score in 
Table I. Nuclear WTAP expression in tumor tissues and clinicopathological features of pancreatic ductal adenocarcinoma.

\begin{tabular}{|c|c|c|c|c|}
\hline \multirow[b]{2}{*}{ Variable } & \multirow{2}{*}{$\begin{array}{l}\text { Patient } \\
\text { number }\end{array}$} & \multicolumn{3}{|c|}{ Nuclear WTAP expression } \\
\hline & & High & Low & P-value \\
\hline Gender $^{\mathrm{b}}$ & & & & 0.010 \\
\hline Male & 85 & 37 & 48 & \\
\hline Female & 54 & 12 & 42 & \\
\hline Age (years) & & & & 0.918 \\
\hline$\geq 65$ & 43 & 15 & 28 & \\
\hline$<65$ & 95 & 34 & 61 & \\
\hline Tumor location & & & & 0.851 \\
\hline Head & 79 & 28 & 51 & \\
\hline Non-head & 54 & 20 & 34 & \\
\hline Tumor size (cm) & & & & 0.290 \\
\hline$\geq 4$ & 98 & 37 & 61 & \\
\hline$<4$ & 39 & 11 & 28 & \\
\hline Histological grade & & & & 0.443 \\
\hline G1-2 & 106 & 35 & 71 & \\
\hline G3-4 & 19 & 8 & 11 & \\
\hline T stage & & & & 0.020 \\
\hline $\mathrm{T} 1-2$ & 81 & 22 & 59 & \\
\hline $\mathrm{T} 3$ & 56 & 26 & 30 & \\
\hline $\mathrm{N}$ stage & & & & 0.512 \\
\hline N0 & 78 & 26 & 52 & \\
\hline $\mathrm{N} 1$ & 54 & 21 & 33 & \\
\hline PNI & & & & 0.687 \\
\hline Present & 69 & 26 & 43 & \\
\hline Absent & 31 & 13 & 18 & \\
\hline
\end{tabular}

${ }^{a} \chi^{2}$ test. Total patient number does not equal 145 in all categories, as patient information was not available for all cases. WTAP, Wilms tumor 1-associated protein; G1, well-differentiated; G2, moderately-differentiated; G3, poorly-differentiated; G4, undifferentiated; $\mathrm{T}$, tumor; N, lymph node; PNI, perineural invasion.

tumor tissues was significantly higher compared with that of non-tumor tissues $(\mathrm{P}<0.001$; Fig. 2). As shown in Table I, high expression of WTAP in the nucleus was significantly associated with gender $(\mathrm{P}=0.010)$ and $\mathrm{T}$ stage $(\mathrm{P}=0.020)$.

Cytoplasmic expression of WTAP in PDAC tissues and its association with clinicopathological features. Positive cytoplasmic WTAP signals were observed in both tumor and non-tumor tissues (Fig. 1A and B). The cytoplasmic WTAP staining score in tumor tissues was significantly higher compared with that of non-tumor tissues $(\mathrm{P}<0.001$; Fig. 3$)$. As shown in Table II, high cytoplasmic expression of WTAP was significantly associated with gender $(\mathrm{P}=0.018)$, histological grade $(\mathrm{P}=0.047)$ and $\mathrm{PNI}(\mathrm{P}=0.028)$.

Prognostic significance of WTAP in PDAC. The prognostic significance of various clinicopathological factors in PDAC patients who underwent radical resection was investigated.
A

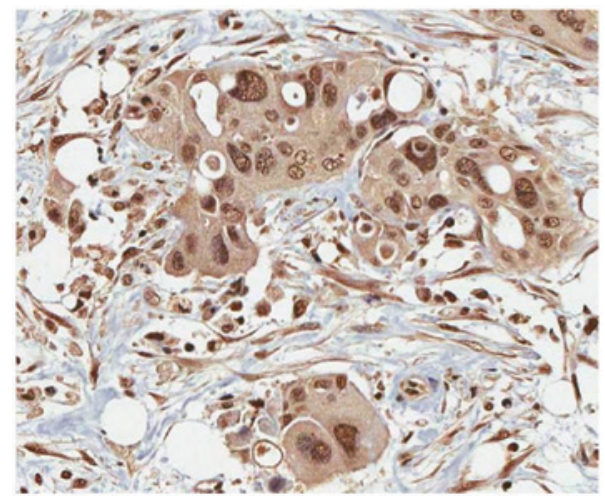

B

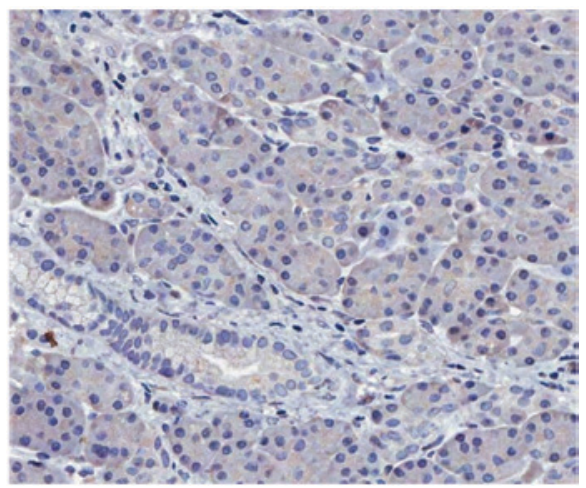

C

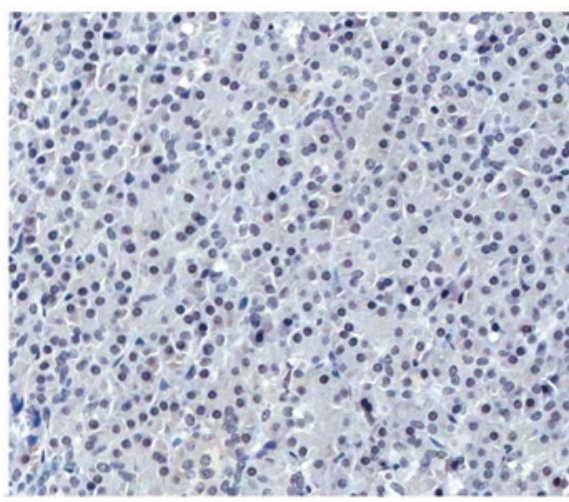

Figure 1. Expression of WTAP in pancreatic ductal adenocarcinoma tissues. (A) Strong nuclear and cytoplasmic WTAP expression in tumor cells. (B) Weak cytoplasmic WTAP expression in non-tumor cells. (C) Negative WTAP expression in control. Magnification x200. WTAP, Wilms tumor 1-associated protein.

For overall survival, univariate analyses demonstrated that patients with high nuclear WTAP expression had a significantly poorer overall survival $(\mathrm{P}<0.001$; Fig. 4; Table III). In addition, gender and $\mathrm{N}$ stage were also prognostic factors in the univariate analysis $(\mathrm{P}=0.006$ and 0.004 , respectively; Table III). A multivariate Cox regression analysis identified nuclear WTAP expression as an independent prognostic indicator of PDAC ( $\mathrm{P}=0.039$; Table III).

\section{Discussion}

WTAP, which is a nuclear protein identified in 2000 (14), has mainly been described in the context of cell proliferation and apoptosis of vascular smooth muscle cells (VSMCs) $(19,20)$. Its ubiquitous expression pattern $(21,22)$ and highly conserved structure indicated that WTAP may act as a house-keeping 
Table II. Cytoplasmic WTAP expression in tumor tissues and clinicopathological features of pancreatic ductal adenocarcinoma.

\begin{tabular}{|c|c|c|c|c|}
\hline \multirow[b]{2}{*}{ Variable } & \multirow{2}{*}{$\begin{array}{l}\text { Patient } \\
\text { number }\end{array}$} & \multicolumn{3}{|c|}{$\begin{array}{c}\text { Cytoplasmic WTAP } \\
\text { expression }\end{array}$} \\
\hline & & High & Low & P-value \\
\hline Gender & & & & 0.018 \\
\hline Male & 85 & 39 & 46 & \\
\hline Female & 54 & 14 & 40 & \\
\hline Age (years) & & & & 0.224 \\
\hline$\geq 65$ & 43 & 13 & 30 & \\
\hline$<65$ & 95 & 39 & 56 & \\
\hline Tumor location & & & & 0.087 \\
\hline Head & 79 & 25 & 54 & \\
\hline Non-head & 54 & 25 & 29 & \\
\hline Tumor size $(\mathrm{cm})$ & & & & 0.417 \\
\hline$\geq 4$ & 98 & 40 & 58 & \\
\hline$<4$ & 39 & 13 & 26 & \\
\hline Histological grade & & & & 0.047 \\
\hline G1-2 & 106 & 36 & 70 & \\
\hline G3-4 & 19 & 8 & 11 & \\
\hline T stage & & & & 0.342 \\
\hline T1-2 & 81 & 34 & 47 & \\
\hline $\mathrm{T} 3$ & 56 & 19 & 37 & \\
\hline $\mathrm{N}$ stage & & & & 0.754 \\
\hline N0 & 78 & 31 & 47 & \\
\hline N1 & 54 & 20 & 34 & \\
\hline PNI & & & & 0.028 \\
\hline Present & 69 & 29 & 40 & \\
\hline Absent & 31 & 6 & 25 & \\
\hline
\end{tabular}

${ }^{a} \chi^{2}$ test. Total patient number does not equal 145 in all categories, as patient information was not available for all cases. WTAP, Wilms tumor 1-associated protein; G1, well-differentiated; G2, moderately-differentiated; G3, poorly-differentiated; G4, undifferentiated; $\mathrm{T}$, tumor; $\mathrm{N}$, lymph node; PNI, perineural invasion.

gene. This was confirmed by the fact that WTAP was shown to be essential for the differentiation of endoderm and mesoderm in the mouse embryo and that WTAP-null and heterozygous mice died at E6.5 and at E10.5, respectively (20).

The WTAP gene was mapped to human chromosome 6q25-27 (14). Interestingly, human chromosome 6q25-27 has been associated with several malignancies, including ovarian cancer (23), renal cell carcinoma (24) and leukemia (25). In addition, as a closely related protein of WT1, which has been shown to be both an oncogene and a tumor suppressor gene (26), it is of interest to investigate whether WTAP is associated with malignances. Previous studies have suggested that WTAP may be a novel oncogene. WTAP was able to promote the migration and invasion of cholangiocarcinoma cells by enhancing the expression of matrix metalloproteinase (MMP) 7, MMP28, cathepsin H and mucin 1, which are

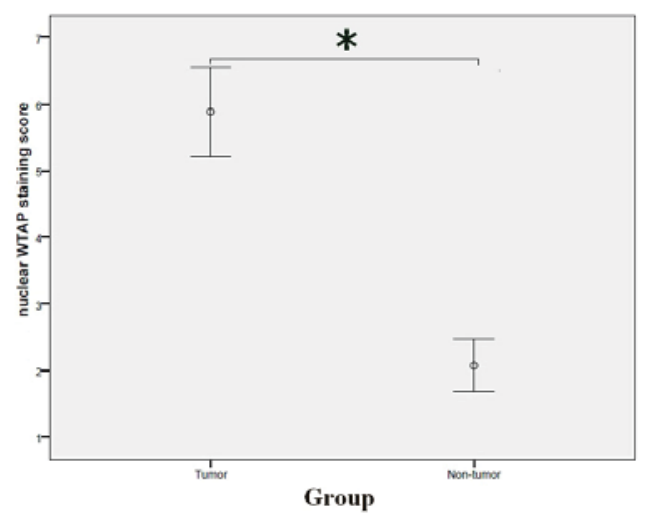

Figure 2. Comparison of the nuclear WTAP expression staining scores between tumor and non-tumor tissues (Mann Whitney U test). Nuclear WTAP expression staining scores in tumor tissues: $5.8828 \pm 4.07823$, nuclear WTAP expression staining scores in non-tumor tissues: $2.0759 \pm 2.40683$. ${ }^{*} \mathrm{P}<0.001$. WTAP, Wilms tumor 1-associated protein.

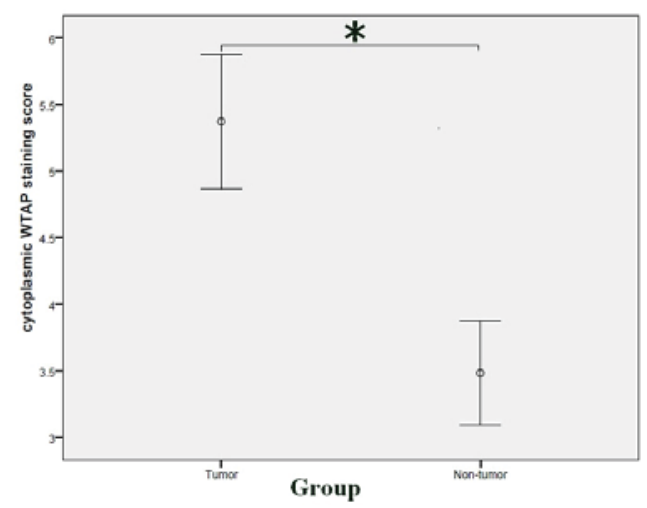

Figure 3. Comparison of the cytoplasmic WTAP expression staining scores between tumor and non-tumor tissues (Mann-Whitney U test). Cytoplasmic WTAP expression staining scores in tumor tissues: $5.3724 \pm 3.07757$, cytoplasmic WTAP expression staining scores in non-tumor tissues: 3.4828 \pm 2.37494 . $* \mathrm{P}<0.001$. WTAP, Wilms tumor 1 -associated protein.

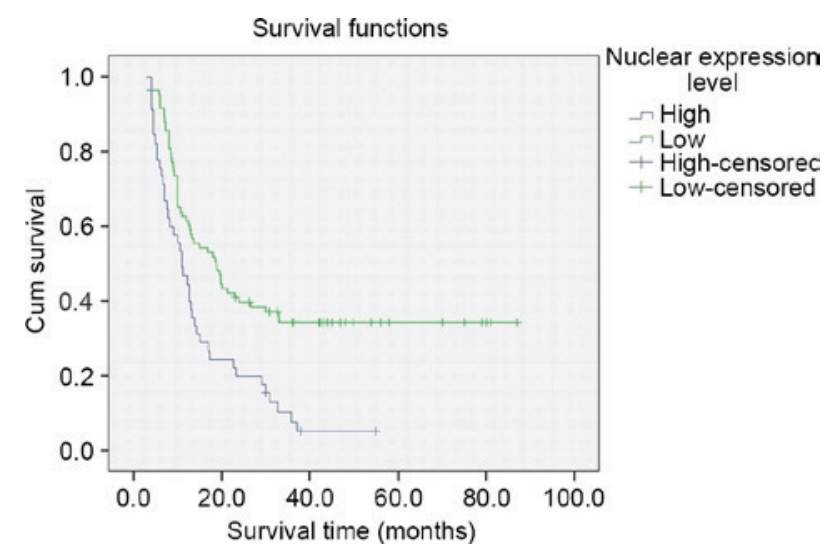

Figure 4. Overall survival of patients with pancreatic ductal adenocarcinoma after surgical resection according to nuclear Wilms tumor 1-associated protein expression in tumor tissues. $\mathrm{P}=0.000$.

enzymes that degrade extracellular matrix components (15). In addition, WTAP was overexpressed in glioblastoma and was associated with the prognosis of patients with glioblastoma (16). Through cDNA microarray experiments, several 
Table III. Predictors of OS in patients with pancreatic ductal adenocarcinoma after resection.

\begin{tabular}{|c|c|c|c|c|c|c|c|}
\hline \multirow[b]{2}{*}{ Variable } & \multicolumn{4}{|c|}{ OS (univariate) } & \multicolumn{3}{|c|}{ OS (multivariate) } \\
\hline & Number & Median $\pm \mathrm{SE}$ & $95 \% \mathrm{CI}$ & $\mathrm{P}^{\mathrm{a}}$ & $\mathrm{RR}$ & $95 \% \mathrm{CI}$ & $\mathrm{P}^{\mathrm{b}}$ \\
\hline Gender & & & & 0.006 & & & 0.920 \\
\hline Male & 85 & $13.00 \pm 1.35$ & $10.36-15.64$ & & 1.036 & $0.520-2.064$ & \\
\hline Female & 54 & $18.90 \pm 6.99$ & $5.20-32.60$ & & 1 & & \\
\hline Age (years) & & & & 0.842 & & & 0.613 \\
\hline$\geq 65$ & 43 & $12.30 \pm 3.85$ & $4.75-19.85$ & & 1.193 & $0.603-2.358$ & \\
\hline$<65$ & 95 & $13.20 \pm 1.21$ & $10.84-15.56$ & & 1 & & \\
\hline Tumor location & & & & 0.337 & & & 0.087 \\
\hline Head & 79 & $13.70 \pm 2.85$ & $8.12-19.29$ & & 1.699 & $0.926-3.119$ & \\
\hline Non-head & 54 & $11.00 \pm 1.85$ & $7.38-14.62$ & & 1 & & \\
\hline Tumor size $(\mathrm{cm})$ & & & & 0.662 & & & 0.721 \\
\hline$\geq 4$ & 98 & $13.00 \pm 2.43$ & $8.24-17.76$ & & 1.119 & $0.605-2.070$ & \\
\hline$<4$ & 39 & $15.00 \pm 3.08$ & $8.97-21.03$ & & 1 & & \\
\hline Histological grade & & & & 0.535 & & & 0.284 \\
\hline G3-4 & 106 & $13.00 \pm 2.68$ & $7.74-18.26$ & & 1.493 & $0.717-3.106$ & \\
\hline G1-2 & 19 & $14.30 \pm 2.35$ & $9.70-18.90$ & & 1 & & \\
\hline T stage & & & & 0.060 & & & 0.051 \\
\hline T3 & 81 & $12.50 \pm 1.16$ & $10.24-14.76$ & & 1.783 & $0.988-3.185$ & \\
\hline T1-2 & 56 & $16.80 \pm 2.99$ & $10.93-22.76$ & & 1 & & \\
\hline $\mathrm{N}$ stage & & & & 0.004 & & & 0.189 \\
\hline N1 & 78 & $11.00 \pm 1.06$ & $8.93-13.27$ & & 1.468 & $0.827-2.611$ & \\
\hline No & 54 & $18.90 \pm 2.92$ & $13.56-24.24$ & & 1 & & \\
\hline PNI & & & & 0.409 & & & 0.245 \\
\hline Present & 69 & $12.70 \pm 1.53$ & $9.70-15.70$ & & 1.456 & $0.773-2.739$ & \\
\hline Absent & 31 & $17.40 \pm 4.14$ & $9.28-25.52$ & & 1 & & \\
\hline Nuclear WTAP expression & & & & 0.000 & & & 0.039 \\
\hline High & 45 & $11.00 \pm 1.54$ & $7.98-14.02$ & & 1.855 & $1.033-3.333$ & \\
\hline Low & 83 & $18.80 \pm 3.09$ & $12.75-24.85$ & & 1 & & \\
\hline Cytoplasmic WTAP expression & & & & 0.256 & & & 0.876 \\
\hline High & 53 & $17.00 \pm 5.20$ & $6.81-27.19$ & & 1.054 & $0.541-2.056$ & \\
\hline Low & 75 & $12.70 \pm 1.43$ & $9.90-15.50$ & & 1 & & \\
\hline
\end{tabular}

${ }^{a}$ Log-rank test; ${ }^{b}$ Multivariate Cox regression test. Total patient number does not equal 145 in all categories, as patient information was not available for all cases. OS, overall survival; SE, standard error; RR, relative risk; CI, confidence interval; G1, well-differentiated; G2, moderately-differentiated; G3, poorly-differentiated; G4, undifferentiated; T, tumor; N, lymph node; PNI, perineural invasion; WTAP, Wilms tumor 1-associated protein; 95\% CI, 95\% confidence interval; P, P-value.

candidate genes downstream of WTAP, including C-C motif chemokine ligand (CCL) 2, CCL3, hyaluronan synthase 1 (HAS1), lysyl oxidase-like (LOXL) 1, MMP3 and thrombospondin 1 (THBS1), were identified (16). Chemokines, including CCL2 and CCL3, have been shown to promote the migration of cancer cells $(27,28)$. LOXL, which oxidizes lysine residues in collagens and elastin, has a promotive role in metastasis by remodeling the tumor microenvironment (29). Hyaluronic acid family proteins including HAS1 have been shown to regulate metastasis (30). THBS1 was a multifunctional matrix protein involved in the migration of cancer cells (31). Besides solid tumors, an oncogenic role for WTAP was also observed in AML (17): By regulating the mammalian target of rapamycin signaling pathway, WTAP promoted the proliferation and induced a differentiation block in AML cells.

To the best of our knowledge, no previous studies have investigated the relationship between WTAP expression and the clinicopathological variables and prognosis of patients with PDAC. The present study demonstrated that WTAP was expressed both in tumor and non-tumor tissues; however, the nuclear expression level of WTAP was significantly higher in tumor tissues than in non-tumor tissues, and high nuclear expression of WTAP was significantly associated with gender and T stage. Furthermore, nuclear WTAP expression was shown to be an independent prognostic indicator of PDAC. However, the function of WTAP in the nucleus remains unknown. 
One possible mechanism is that WTAP is able to regulate the transcriptional activity of WT1 by binding to it. In VSMCs, it was shown that WT1 exerted its anti-proliferative and pro-apoptotic activities via the WTAP-WT1 axis, of which the target genes included amphiregulin (32), a potential VSMC mitogen (33), and B-cell lymphoma (Bcl)-2 (34), which has also been shown to exert an anti-apoptotic role in VSMCs (35). WT1 is a well-known tumor suppressor gene in Wilms' tumor (26). However, data have accumulated regarding an oncogenic role for WT1 in various adult tumors, including colorectal (36), breast (37), desmoid (38), pancreatic (39) and brain tumors (40). The bi-directional control of the mesenchymal-epithelial transition $(41,42)$ may partially explain how WT1 is able to function as a tumor suppressor gene in some tissues and as a potential oncogene in others. Furthermore, the WTAP-WT1 axis may account for the different effects of WTAP in different cell types, as the function of WT1 is known to vary in different contexts (26). Therefore, it is likely that WTAP has an oncogenic role in PDAC via the WTAP-WT1 axis, although this requires further investigation.

Another possible mechanism is that WTAP is involved in pre-mRNA splicing, which has been reported in VSMCs (43). Approximately $94 \%$ of genes were estimated to be alternatively spliced in humans, driving the proteome diversity $(44,45)$. During oncogenesis and tumor progression, cells undergo various processes, including sustaining proliferative signaling, evading growth suppressors, resisting cell death, enabling replicative immortality, inducing angiogenesis, activating invasion and metastasis, reprogramming of energy metabolism and evading immune destruction (46). Importantly, it has been reported that alternative splicing regulates many of these processes (47). For instance, de4 epidermal growth factor receptor (EGFR), a splice variant of EGFR, which is a member of the receptor tyrosine kinases family and has a central role in cell proliferation and motility through downstream signaling mediators, functions as a receptor that was constitutively active and promoted proliferation in gliomas and prostate and ovarian cancer (48). In addition, alternative splicing of Bcl-x produced a short isoform that was pro-apoptotic, and a long isoform that was anti-apoptotic (49). The balance of these two isoforms affected different types of cancer cell lines and human cancer samples differently (50-52). $\Delta$ Ron, which is a specific isoform of Ron generated by skipping of exon 11 by alternative splicing, conferred an increased motility on cancer cells and was upregulated in several types of cancers (53). Therefore, it is likely that WTAP plays an oncogenic role in the nucleus by regulating cancer-associated pre-mRNA splicing in PDAC.

The present study demonstrated that the cytoplasmic WTAP staining score of tumor tissues was significantly higher than that of non-tumor tissues, and high WTAP cytoplasmic expression was significantly associated with gender, histological grade and PNI. One possible mechanism for cytoplasmic WTAP to accelerate the PNI and dedifferentiation of PDAC cells is through its specific interaction with WT1. Although WT1 predominantly existed in the nucleus, a previous study demonstrated that WT1 underwent nucleocytoplasmic shuttling (54), which means WT1 may also participate in some cellular processes occurring in the cytoplasm. WT1 may be divided into two major isoforms, depending on the presence or absence of lysine-threonine-serine (KTS): +KTS and
-KTS (14). Shuttling occurred with both the +KTS and the -KTS isoforms, which led to their association with actively translating polysomes (55). It is not yet clear what function is served by WT1 associating with the polysomes, but it adds a further dimension to the potential functions of the WTAP-WT1 axis in cancer formation and progression.

Another possible mechanism is its role in mRNA stabilization. In human umbilical vein endothelial cells, WTAP enhanced cyclin A2 mRNA stability by binding to its 3'-untranslated region (UTR) (20). However, other studies suggested that WTAP was able to accelerate the degradation of target mRNAs by promoting N6-methyladenosine (m6A) formation. In one study, WTAP was shown to form a complex with the methyltransferase-like (METTL) 3/METTL14 heterodimer to catalyze m6A formation (56). In another study, the C-terminal domain of YTH m6A RNA binding protein 2 selectively bound to m6A-containing mRNA, resulting in the translocation of the bound mRNA from the translatable pool to mRNA decay sites (57). These findings suggested that WTAP may negatively correlate with the stability of its target mRNAs. The regulation of mRNA stability has been recognized as an important process in the control of gene expression. The best-characterized cis-element that mediates mRNA degradation is the AU-rich element (58), which is present in the 3'-UTR of numerous mRNAs, including those of growth factors $(59)$, oncogenes $(60)$, cytokines $(61,62)$ and cell-cycle regulatory proteins $(63,64)$. Although WTAP has been shown to have a dual role in mRNA stability, the mRNAs of the above genes may be the downstream targets mediating its oncogenic role in the cytoplasm.

In conclusion, the results of the present study suggested that both nuclear and cytoplasmic WTAP was highly expressed in PDAC and that high nuclear expression of WTAP was a valuable molecular biomarker of a poor prognosis among PDAC patients.

\section{References}

1. Siegel RL, Miller KD and Jemal A: Cancer statistics, 2015. CA Cancer J Clin 65: 5-29, 2015.

2. Torre LA, Bray F, Siegel RL, Ferlay J, Lortet-Tieulent J and Jemal A: Global cancer statistics 2012. CA Cancer J Clin 65: 87-108, 2015.

3. Siegel RL, Miller KD and Jemal A: Cancer statistics, 2016. CA Cancer J Clin 66: 7-30, 2016.

4. Wang L, Yang GH, Lu XH, Huang ZJ and Li H: Pancreatic cancer mortality in China (1991-2000). World J Gastroenterol 9: 1819-1823, 2003.

5. Hidalgo M: Pancreatic cancer. N Engl J Med 362: 1605-1617, 2010.

6. Rahib L, Smith BD, Aizenberg R, Rosenzweig AB, Fleshman JM and Matrisian LM: Projecting cancer incidence and deaths to 2030: The unexpected burden of thyroid, liver, and pancreas cancers in the United States. Cancer Res 74: 2913-2921, 2014.

7. Afaneh C, Gerszberg D, Slattery E, Seres DS, Chabot JA and Kluger MD: Pancreatic cancer surgery and nutrition management: A review of the current literature. Hepatobiliary Surg Nutr 4: 59-71, 2015.

8. Oettle H, Post S, Neuhaus P, Gellert K, Langrehr J, Ridwelski K, Schramm H, Fahlke J, Zuelke C, Burkart C, et al: Adjuvant chemotherapy with gemcitabine vs observation in patients undergoing curative-intent resection of pancreatic cancer: A randomized controlled trial. JAMA 297: 267-277, 2007.

9. Robinson SM, Rahman A, Haugk B, French JJ, Manas DM, Jaques BC, Charnley RM and White SA: Metastatic lymph node ratio as an important prognostic factor in pancreatic ductal adenocarcinoma. Eur J Surg Oncol 38: 333-339, 2012. 
10. Chatterjee D, Katz MH, Rashid A, Wang H, Iuga AC Varadhachary GR, Wolff RA, Lee JE, Pisters PW, Crane CH, et al: Perineural and intraneural invasion in postherapy pancreaticoduodenectomy specimens predicts poor prognosis in patients with pancreatic ductal adenocarcinoma. Am J Surg Pathol 36: 409-417, 2012

11. Zhang Y, Frampton AE, Cohen P, Kyriakides C, Bong JJ, Habib NA, Spalding DR, Ahmad R and Jiao LR: Tumor infiltration in the medial resection margin predicts survival after pancreaticoduodenectomy for pancreatic ductal adenocarcinoma. J Gastrointest Surg 16: 1875-1882, 2012.

12. Ansari D, Rosendahl A, Elebro J and Andersson R: Systematic review of immunohistochemical biomarkers to identify prognostic subgroups of patients with pancreatic cancer. Br J Surg 98: 1041-1055, 2011.

13. Winter JM, Yeo CJ and Brody JR: Diagnostic, prognostic, and predictive biomarkers in pancreatic cancer. J Surg Oncol 107: 15-22, 2013.

14. Little NA, Hastie ND and Davies RC: Identification of WTAP, a novel Wilms' tumour 1-associating protein. Hum Mol Genet 9: 2231-2239, 2000.

15. Jo HJ, Shim HE, Han ME, Kim HJ, Kim KS, Baek S, Choi KU, Hur GY and Oh SO: WTAP regulates migration and invasion of cholangiocarcinoma cells. J Gastroenterol 48: 1271-1282, 2013.

16. Jin DI, Lee SW, Han ME, Kim HJ, Seo SA, Hur GY, Jung S, Kim BS and Oh SO: Expression and roles of Wilms' tumor 1-associating protein in glioblastoma. Cancer Sci 103: 2102-2109, 2012.

17. Bansal H, Yihua Q, Iyer SP, Ganapathy S, Proia DA, Penalva LO, Uren PJ, Suresh U, Carew JS, Karnad AB, et al: WTAP is a novel oncogenic protein in acute myeloid leukemia. Leukemia 28 1171-1174, 2014.

18. Klöppel G, Hruban RH, Longnecker DS, et al: Ductal adenocarcinoma of the pancreas. In: World Health Organization Classification of Tumours. Pathology and Genetics of Tumours of the Digestive System. Hamilton SR and Aaltonen LA (eds). Vol 2. IARC Press, Lyon, pp211-230, 2000.

19. Small TW, Bolender Z, Bueno C, O'Neil C, Nong Z, Rushlow W, Rajakumar N, Kandel C, Strong J, Madrenas J and Pickering JG: Wilms' tumor 1-associating protein regulates the proliferation of vascular smooth muscle cells. Circ Res 99: 1338-1346, 2006.

20. Horiuchi K, Umetani M, Minami T, Okayama H, Takada S, Yamamoto M, Aburatani H, Reid PC, Housman DE, Hamakubo T and Kodama T: Wilms' tumor 1-associating protein regulates G2/M transition through stabilization of cyclin A2 mRNA. Proc Natl Acad Sci USA 103: 17278-17283, 2006.

21. Armstrong JF, Pritchard Jones K, Bickmore WA, Hastie ND and Bard JB: The expression of the Wilms' tumour gene, WT1, in the developing mammalian embryo. Mech Dev 40: 85-97, 1993.

22. Buckler AJ, Pelletier J, Haber DA, Glaser T and Housman DE: Isolation, characterization, and expression of the murine Wilms tumor gene (WT1) during kidney development. Mol Cell Biol 11: $1707-1712,1991$

23. Cooke IE, Shelling AN, Le Meuth VG, Charnock ML and Ganesan TS: Allele loss on chromosome arm $6 \mathrm{q}$ and fine mapping of the region at $6 \mathrm{q} 27$ in epithelial ovarian cancer. Genes Chromosomes Cancer 15: 223-233, 1996.

24. Morita R, Saito S, Ishikawa J, Ogawa O, Yoshida O, Yamakawa K and Nakamura Y: Common regions of deletion on chromosomes 5q, 6q, and 10q in renal cell carcinoma. Cancer Res 51: 5817-5820, 1991.

25. Menasce LP, Orphanos V, Santibanez-Koref M, Boyle JM and Harrison CJ: Common region of deletion on the long arm of chromosome 6 in non-Hodgkin's lymphoma and acute lymphoblastic leukaemia. Genes Chromosomes Cancer 10: 286-288, 1994.

26. Hohenstein P and Hastie ND: The many facets of the Wilms tumour gene, WT1. Hum Mol Genet 15: 196-201, 2006.

27. Chiu HY, Sun KH, Chen SY, Wang HH, Lee MY, Tsou YC Jwo SC, Sun GH and Tang SJ: Autocrine CCL2 promotes cell migration and invasion via PKC activation and tyrosine phosphorylation of paxillin in bladder cancer cells. Cytokine 59: 423-432, 2012

28. Akashi T, Koizumi K, Nagakawa O, Fuse H and Saiki I: Androgen receptor negatively influences the expression of chemokine receptors (CXCR4, CCR1) and ligand-mediated migration in prostate cancer DU-145. Oncol Rep 16: 831-836, 2006.

29. Xiao Q and Ge G: Lysyl oxidase, extracellular matrix remodeling and cancer metastasis. Cancer Microenviron 5: 261-273, 2012.
30. Kramer MW, Escudero DO, Lokeshwar SD, Golshani R, Ekwenna OO, Acosta K, Merseburger AS, Soloway M and Lokeshwar VB: Association of hyaluronic acid family members (HAS1, HAS2, and HYAL-1) with bladder cancer diagnosis and prognosis. Cancer 117: 1197-1209, 2011.

31. Roberts DD: Regulation of tumor growth and metastasis by thrombospondin-1. FASEB J 10: 1183-1191, 1996.

32. Lee SB, Huang K, Palmer R, Truong VB, Herzlinger D, Kolquist KA, Wong J, Paulding C, Yoon SK, Gerald W, et al: The Wilms tumor suppressor WT1 encodes a transcriptional activator of amphiregulin. Cell 98: 663-673, 1999.

33. Shin HS, Lee HJ, Nishida M, Lee MS, Tamura R, Yamashita S, Matsuzawa Y, Lee IK and Koh GY: Betacellulin and amphiregulin induce upregulation of cyclin D1 and DNA synthesis activity through differential signaling pathways in vascular smooth muscle cells. Circ Res 93: 302-310, 2003.

34. Mayo MW, Wang CY, Drouin SS, Madrid LV, Marshall AF, Reed JC, Weissman BE and Baldwin AS: WT1 modulates apoptosis by transcriptionally upregulating the bcl-2 proto-oncogene. EMBO J 18: 3990-4003, 1999.

35. Perlman H, Sata M, Krasinski K, Dorai T, Buttyan R and Walsh K: Adenovirus-encoded hammerhead ribozyme to Bcl-2 inhibits neointimal hyperplasia and induces vascular smooth muscle cell apoptosis. Cardiovasc Res 45: 570-578, 2000.

36. Koesters R, Linnebacher M, Coy JF, Germann A, Schwitalle Y, Findeisen P and von Knebel Doeberitz M: WT1 is a tumor-associated antigen in colon cancer that can be recognized by in vitro stimulated cytotoxic T cells. Int J Cancer 109: 385-392, 2004

37. Loeb DM, Evron E, Patel CB, Sharma PM, Niranjan B, Buluwela L, Weitzman SA, Korz D and Sukumar S: Wilms' tumor suppressor gene (WT1) is expressed in primary breast tumors despite tumor-specific promoter methylation. Cancer Res 61: 921-925, 2001.

38. Amini Nik S, Hohenstein P, Jadidizadeh A, Van Dam K, Bastidas A, Berry RL, Patek CE, Van der Schueren B Cassiman JJ and Tejpar S: Upregulation of Wilms' tumor gene 1 (WT1) in desmoid tumors. Int J Cancer 114: 202-208, 2005.

39. Oji Y, Nakamori S, Fujikawa M, Nakatsuka S, Yokota A, Tatsumi N, Abeno S, Ikeba A, Takashima S, Tsujie M, et al: Overexpression of the Wilms' tumor gene WT1 in pancreatic ductal adenocarcinoma. Cancer Sci 95: 583-587, 2004

40. Oji Y, Suzuki T, Nakano Y, Maruno M, Nakatsuka S, Jomgeow T, Abeno S, Tatsumi N, Yokota A, Aoyagi S, et al: Overexpression of the Wilms' tumor gene WT1 in primary astrocytic tumors. Cancer Sci 95: 822-827, 2004.

41. Davies JA, Ladomery M, Hohenstein P, Michael L, Shafe A Spraggon L and Hastie N: Development of an siRNA-based method for repressing specific genes in renal organ culture and its use to show that the Wt1 tumour suppressor is required for nephron differentiation. Hum Mol Genet 13: 235-246, 2004.

42. Moore AW, McInnes L, Kreidberg J, Hastie ND and Schedl A: YAC complementation shows a requirement for Wt1 in the development of epicardium, adrenal gland and throughout nephrogenesis. Development 126: 1845-1857, 1999.

43. Horiuchi K, Kawamura T, Iwanari H, Ohashi R, Naito M, Kodama $\mathrm{T}$ and Hamakubo T: Identification of Wilms' tumor 1-associating protein complex and its role in alternative splicing and the cell cycle. J Biol Chem 288: 33292-33302, 2013.

44. Pan Q, Shai O, Lee LJ, Frey BJ and Blencowe BJ: Deep surveying of alternative splicing complexity in the human transcriptome by high-throughput sequencing. Nat Genet 40: 1413-1415, 2008.

45. Wang ET, Sandberg R, Luo S, Khrebtukova I, Zhang L, Mayr C, Kingsmore SF, Schroth GP and Burge CB: Alternative isoform regulation in human tissue transcriptomes. Nature 456: 470-476, 2008.

46. Hanahan D and Weinberg RA: Hallmarks of cancer: The next generation. Cell 144: 646-667, 2011.

47. Oltean S and Bates DO: Hallmarks of alternative splicing in cancer. Oncogene 33: 5311-5318, 2014

48. Wang H, Zhou M, Shi B, Zhang Q, Jiang H, Sun Y, Liu J, Zhou K, Yao M, Gu J, et al: Identification of an exon 4-deletion variant of epidermal growth factor receptor with increased metastasis-promoting capacity. Neoplasia 13: 461-471, 2011.

49. Cloutier P, Toutant J, Shkreta L, Goekjian S, Revil T and Chabot B: Antagonistic effects of the SRp30c protein and cryptic 5 'splice sites on the alternative splicing of the apoptotic regulator Bcl-x. J Biol Chem 283: 21315-21324, 2008.

50. Reeve JG, Xiong J, Morgan J and Bleehen NM: Expression of apoptosis-regulatory genes in lung tumour cell lines: Relationship to $\mathrm{p} 53$ expression and relevance to acquired drug resistance. $\mathrm{Br} \mathrm{J}$ Cancer 73: 1193-1200, 1996. 
51. Krajewska M, Krajewski S, Epstein JI, Shabaik A, Sauvageot J, Song K, Kitada S and Reed JC: Immunohistochemical analysis of bcl-2, bax, bcl-X, and mcl-1 expression in prostate cancers. Am J Pathol 148: 1567-1576, 1996.

52. Krajewska M, Moss SF, Krajewski S, Song K, Holt PR and Reed JC: Elevated expression of Bcl-X and reduced Bak in primary colorectal adenocarcinomas. Cancer Res 56: 2422-2427, 1996.

53. Ghigna C, Giordano S, Shen H, Benvenuto F, Castiglioni F, Comoglio PM, Green MR, Riva S and Biamonti G: Cell motility is controlled by SF2/ASF through alternative splicing of the Ron protooncogene. Mol Cell 20: 881-890, 2005.

54. Vajjhala PR, Macmillan E, Gonda T and Little M: The Wilms tumour suppressor protein, WT1, undergoes CRM1-independent nucleocytoplasmic shuttling. FEBS Lett 554: 143-148, 2003.

55. Niksic M, Slight J, Sanford JR, Caceres JF and Hastie ND: The Wilms' tumour protein (WT1) shuttles between nucleus and cytoplasm and is present in functional polysomes. Hum Mol Genet 13: 463-471, 2004.

56. Ping XL, Sun BF, Wang L, Xiao W, Yang X, Wang WJ, Adhikari S, Shi Y, Lv Y, Chen YS, et al: Mammalian WTAP is a regulatory subunit of the RNA N6-methyladenosine methyltransferase. Cell Res 24: 177-189, 2014.

57. Wang X, Lu Z, Gomez A, Hon GC, Yue Y,Han D, Fu Y, Parisien M, Dai Q, Jia G, et al: N6-methyladenosine-dependent regulation of messenger RNA stability. Nature 505: 117-120, 2014.
58. Chen CY and Shyu AB: AU-rich elements: Characterization and importance in mRNA degradation. Trends Biochem Sci 20: 465-470, 1995.

59. Shaw G and Kamen R: A conserved AU sequence from the 3' untranslated region of GM-CSF mRNA mediates selective mRNA degradation. Cell 46: 659-667, 1986.

60. Miller AD, Curran T and Verma IM: c-fos protein can induce cellular transformation: A novel mechanism of activation of a cellular oncogene. Cell 36: 51-60, 1984.

61. Henics T, Sanfridson A, Hamilton BJ, Nagy E and Rigby WF: Enhanced stability of interleukin-2 mRNA in MLA 144 cells. Possible role of cytoplasmic AU-rich sequence-binding proteins. J Biol Chem 269: 5377-5383, 1994.

62. Wodnar-Filipowicz A and Moroni C: Regulation of interleukin 3 mRNA expression in mast cells occurs at the posttranscriptional level and is mediated by calcium ions. Proc Natl Acad Sci USA 87: 777-781, 1990.

63. Lal A, Mazan-Mamczarz K, Kawai T, Yang X, Martindale JL and Gorospe M: Concurrent versus individual binding of HuR and AUF1 to common labile target mRNAs. EMBO J 23: 3092-3102, 2004

64. Lin S, Wang W, Wilson GM, Yang X, Brewer G, Holbrook NJ and Gorospe M: Down-regulation of cyclin D1 expression by prostaglandin $\mathrm{A}(2)$ is mediated by enhanced cyclin D1 mRNA turnover. Mol Cell Biol 20: 7903-7913, 2000. 